\title{
'Where Have All the Students Gone?' Absenteeism in a Turkish State University English Language Preparatory Year
}

\author{
Wayne Trotman ${ }^{1}$ \\ ${ }^{1}$ School of Foreign Languages, Izmir Katip Çelebi University, Turkey \\ Correspondence: Wayne Trotman, School of Foreign Languages, Izmir Katip Çelebi University, Izmir, Turkey. \\ E-mail: waynetrotman@gmail.com
}

Received: January 29, 2016

Accepted: February 3, 2016

Online Published: February 29, 2016

doi:10.20849/aes.v1i1.32

URL: http://dx.doi.org/10.20849/aes.v1i1.32

\begin{abstract}
Research presented here adopted a mixed method approach to data gathering in order to provide a case study that investigated reasons for students in a higher education context in Turkey failing the year due to repeated absenteeism. A survey administered to 109 students and 43 teachers revealed varying reasons and perceptions of why students were absent from language lessons. Individual and follow-up interviews with ten students revealed how absence was due largely to logistical and personal problems, principally commitment and motivation, rather than those related to learning or teaching, which reflects Longhurst (1999). Based upon these points, it is clear that in order to maximise language learning opportunities in the university preparatory year, the issue of both potential and actual students failing due to absenteeism (SFDA) requires urgent address.
\end{abstract}

Keywords: absenteeism, case study, interviews, qualitative research

\section{Introduction}

A good deal of research into language teaching and learning concerns what takes place within the hearts and minds of people present in the classroom. Although the international literature as a whole shows a strong interest in student absenteeism, e.g. Romer's (1993) seminal study of students of Economics in the USA, considerably less of a focus has been on why students absent themselves from second language learning classrooms, and the consequences of doing so. This study took place in a recently opened state university in Turkey (henceforth referred to as ' $\mathrm{CK}$ '). It investigated the amount of students failing the preparatory year due to being absent for no official reason (SFDA). As well as providing a profile of these 'silent withdrawals' and their reasons for not being present when language teaching is taking place, it also puts forward possible solutions to this issue. It is, therefore, a case study involving mixed methods research into why students opt out of language lessons. The study recognises that university is not an extension of school, and that while they need to be treated as adults, students also need to know that exceeding the limit of time allowed for absence may have serious consequences.

\section{Literature Review}

Several articles in the literature provide evidence of a relationship between attendance and academic success, e.g. Burd and Hodgson (2006), while others have noted a correlation between attendance and remaining on or departing from courses, e.g Cleary-Holdforth (2007). One widely quoted study of student absenteeism is Schalge and Soga (2008) who adopted an ethnographic approach to investigate factors resulting in a cycle of absenteeism on an adult ESL programme in the USA. Their study, one which did not deal with students who failed directly due to absenteeism, adopted a 'cultural broker framework model' which asks educators to understand learners' viewpoints, but not vice-versa (Ervin, 2000). The study reports on the divergent perspectives of teachers, students and administrators. Their chief finding was that '..more effective communication between teachers and students regarding curriculum content and expected outcomes was a key factor in reducing absenteeism', and that 'When students commented that classes were 'boring', their views came from anxiety about unpredictable learning topics or veiled curriculum objectives'(Schalge \& Soga, 2008). As a solution the study also noted how '..more careful estimations of students' abilities ensures effective communication and helps students develop a sense of ownership of their learning.' (ibid).

Researching student absenteeism in a further education college in the UK, from semi-structured interviews 
Longhurst (1999) located fifteen categories of reasons for absence. Interestingly, factors relating to the courses and teachers were found to be the least significant. Evidence was revealed to support the notion that students' general degree of commitment to education may be the most important factor related to levels of absenteeism. Discounting illness and medical appointments, for which students can claim official absence, the top five reasons Longhurst (1999) noted for absence were as follows, ranging from most to less likely: weather conditions; social activities; doing college work; transport problems; being with friends from college. Suggested solutions include developing 'modes of learning whereby the presence of students in classes in college is less important - more self-supported and distance learning' (Longhurst, 1999, p.75).

Unlike the present study, of the above only Schalge and Soga (2008) was related to language teaching; the others concerned colleges of general higher education. None attempted to relate end of year failure to absenteeism. While several studies have been carried out concerning student absenteeism in Turkey, they have been related mainly to health science faculties, e.g. Batı, Mandiricioğlu, Orgun and Govsa (2012) who noted sleeping disorders as a key reason. Surprisingly, and based upon empirical evidence that suggests absenteeism is endemic there, studies into this area in relation to language students in the preparatory year in Turkey appear relatively non-existent.

\section{Context: The Preparatory Year}

At the beginning of the academic year in Turkey all students are invited to take a language proficiency exam which serves as a placement test. If they attain a suitable score, usually 70 and above which it is felt corresponds to B1 and above on the Common European Framework of Reference (CEFR), they are allowed to proceed to studying in their faculty. At CK, however, not all faculties are taught in English. Mechanical Engineering is completely in English, Economics is $30 \%$ in English, but Sociology, Tourism Guidance and Business Administration are in Turkish. Students who fail to turn up for the exam and those attaining less than the required score are obliged to take the English preparatory year. In order to pass, by the end of the year students are expected to be at or very near to B1 level on the CEFR. Students who completely fail the preparatory year are allowed to repeat the year only once. Further failure means they will have to re-take the university entrance exam in order to apply for Turkish medium of instruction courses.

A1 level students (beginners) were timetabled to have twenty-two English lessons per week, while those at A2 level were timetabled to have twenty. Teachers are legally obliged to collect students' signatures of attendance for each lesson and add those missed to an official database at the end of each week. At the start of the academic year students are informed of the relevant web page to check on their absenteeism record. Theoretically at least, they thus have no reason to complain about 'not knowing the score'. Throughout this study official help on the campus in the student counselling office was available for students who were having problems adapting to higher education. Students had been invited to attend a presentation concerning this during the orientation week prior to the academic year.

Although percentages vary, and are set by individual university authorities in Turkey, on the one-year intensive English language preparatory course this study was concerned with, students in A1 (beginner) level classes absent for more than 88 lessons (15\%) automatically failed the year. A2 classes were allowed to miss up to the same percentage ( 80 lessons). These figures are to allow for absence through illness, which is not the concern of this study.

\subsection{Issues Affecting Attendance}

Although the regulation tends to vary among universities in Turkey, at university CK in the year this study took place (2015), SFDAs were allowed to take the end of year proficiency exam to enable them to proceed to faculty study and participate in the summer school in order to re-sit the same exam which may be viewed as being rather generous and may encourage absenteeism. The fact that the amount of teaching in English in some departments at $\mathrm{CK}$ varies tends to affect motivation towards attending classes. At the start of the year one hundred and fifty of the seven hundred and twenty-eight students were attending the preparatory year already safe in the knowledge that they would, in spite of becoming an SFDA, automatically pass.

\section{Methodology}

Research outlined here recognises the 'definitial penumbra' (Gerring, 2007) concerning what a case study actually is. This study works on the premise that a case study investigates the particularity and complexity of a single case, coming to understand its activity within important circumstances (Stake, 1995). In the current study it is the in-depth analysis of instances of the phenomenon of SFDAs in their natural context. It is written from the perspectives of participants involved (Gall, J. P., Gall, M. D., \& Borg, 2005) and works on the principle that the 
SFDA is a group that was analysed as an integrated social unit which was studied holistically and in its particularity (Schutt, 2006). As it looks at a representative sample of ten potential SFDAs over a period of one academic year, it is both a cross-sectional and longitudinal study. Throughout this year it involved iteration, moving repeatedly from data collection to analysis.

This study satisfies Richards' (2011) essential characteristics for a case study in that it was largely situated but also axial, i.e. it was a study of a group in itself that physically existed, but one which at the same time sought to shed light on features of a larger group to which it belonged. It was largely intrinsic but also instrumental, i.e. the starting point was interest in the particular case of SFDAs at the university under focus because it raised questions that needed to be answered there, but at the same time it investigated broader issues of SFDAs elsewhere. It consisted of both the uniqueness of SFDAs at the university and had commonality in that many of the reasons for, and suggested solutions to, SFDA issues there could be applied to universities elsewhere in Turkey. It was studied in its natural context and recognised the need for (but possible elusiveness of) anonymity. All possible data identifying participants and the institution were removed; students interviewed were shown accounts of their interviews. As it involved qualitative and quantitative questionnaire surveys and semi-structured in-depth initial and follow-up interviews with both students and teachers, it thus drew upon multiple data gathering sources (Richards, 2011).

\subsection{Research Focus}

This study outlines and investigates the case of SFDAs in the preparatory year at a state university in Turkey. Who are they and what is their profile? What are students', teachers' and administrators' perceptions of reasons for student absenteeism? More importantly, what can be done to resolve the case of the SFDA?

\subsection{Absenteeism Data}

As Table 1 illustrates, in 2012/13 (the first at CK) the intake in the preparatory year was 223 students. By the end of the year this figure had fallen to 167 students eligible to take the proficiency exam,a decrease of $25 \%$. How many failed due to absenteeism (and at which levels) is impossible to locate as such data was at the time not recorded, but administrative staff estimate this as between $15 \%$ and $20 \%$. In 2013/14 the intake in the preparatory year stood at 633 ; by the end this had fallen by 125 SFDA to 508 , a decrease of $20 \%$. Due to the availability of more details, during the same year A1 level students in semester one numbered 554 (88\% of the total). This figure fell by 111 to 443 , a decrease of $20 \%$. Over the same period the number of students at A2 level decreased from 79 to $67: 15 \%$.

Table 1. Student Attrition 2012 - 2014

\begin{tabular}{lccc}
\hline Academic Year & Starting the year & Ending the year & $\%$ SFDA \\
\hline $2012-2013$ total & 223 & 167 & $15-20 \%$ \\
$2013-2014$ total & 633 & 508 & $20 \%$ \\
A1 & 554 & 443 & $20 \%$ \\
A2 & 79 & 67 & $15 \%$ \\
\hline
\end{tabular}

\subsection{Background to Data Collection and Analysis}

The case focused upon in this study was SFDAs from the intake of students for the 2014-2015 academic year. Initial data gathered was collected from the adminstrative office during week fiveof semester one which ran for fourteen weeks, by which time the first group of SFDAs had appeared due to exceeding absence in more than $15 \%$ for the year's language lessons. This is illustrated in Table 2.

Table 2. Student attrition: 2014 - 2015

\begin{tabular}{lcccc}
\hline 2014-2015 Total & Starting the year: 728 & End of Semester 1: 684 & End of Semester 2: 589 & \%SFDAs \\
\hline 2014-2015: A1 & 570 & 530 & 448 & $21.5 \%$ \\
2014-2015: A2 & 158 & 154 & 141 & $11.2 \%$ \\
\hline
\end{tabular}

728 students began the preparatory year. This was made up of 570 in A1 classes and 158 in A2 (an increase from 
a total of 223 in year one and 633 in year two). By the end of the year 122 students from A1 had become an SFDA statistic: $21.5 \%$, while at the same stage only 17 out of 158 A2 students had achieved the same status: $11.2 \%$. The overall figure for SFDAs in $2014-2005$ was 139: 19\% of those who had begun the year. Of the 589 students who made it to the end of the year without becoming an SFDA, 431 had achieved an average of $60 \%$ on mid-term exams and were able to enter the proficiency exam, of which approximately $50 \%$ passed.

\subsection{Data Collection Issues}

As the semester continued I realised that SFDAs would more than likely disappear from the campus once they had gone over their limit of 15\%; contacting them would be almost impossible. To pre-empt this I requested the student affairs office inform me of students who were approaching the limit so that I could arrange an interview. For convenience, interviews were when possible conducted solely in English. On occasions (as my own Turkish is limited to about B1 level) they were conducted with the help of a Turkish speaking colleague to interpret where necessary. Although the original intention had been to partially replicate the study by Longhurst (1999) and enable coding and categorising data based on open-ended interviews, this proved impossible. Attempts floundered as several students on the verge of failing that I tried to interview were reluctant to discuss what for them was clearly a delicate matter. One, for example, was clearly concerned that his parents might via this study hear about his early departure from the preparatory year; he clearly had no plans to inform them. I therefore decided to gather data at this stage by other means.

\section{Introduction to Analysis}

The first part of data gathering involved designing and administering a questionnaire to teachers and students to gain insights into their perceptions of student absenteeism. The second involved carrying out semi-structured interviews with ten potential SFDAs and five teachers. The third and final part consisted of follow-up interviews with seven of the ten students previously interviewed (by this stage three had already become SFDA statistics). Accounts of both interviews appear together.

\subsection{Analysis Part One: Teacher Perceptions}

The questionnaire was translated into Turkish, largely for the benefit of SFDAs who were, due to their situation, more than likely to be unable to fully understand the original version in English. The English version of the questionnaire appears in Appendix 1. Research firstly looked at teachers' perceptions of student absenteeism in the preparatory year.

The thirteen items are largely taken from Longhurst (1999) with some adaptations. Column two in both tables (N) indicates how many times this item was ranked; column three indicates the average of these rankings. In order to measure their perceptions teachers were asked to rank ten of the thirteen items in relation to the likelihood of reasons for student absenteeism. Having had bitter experience on earlier research projects with emailing questionnaires and receiving very few in return, I visited and personally explained to each teacher exactly what was required of them regarding completing the survey. Teachers awarded the most likely reason as number ten, moving down to number one for the least likely of their choices.This was extremely time-consuming but,by the end, forty-three teachers and administrators had provided completed questionnaires with ten items selected and ranked. The mean scores for each item after SPSS (Statistical Package for Social Scientists) analysis are shown in Table 3.

Table 3. Teacher perceptions for student absence

\begin{tabular}{lcc}
\hline Reason & Number of times selected & Mean score \\
\hline Transport & 32 & 8.34 \\
Disliking lessons & 28 & 7.96 \\
\hline
\end{tabular}

Not recorded in Table 3 are the following comments which teachers added in the space available for 'Other reasons'. 'Sleeping problems' was listed by four teachers. Others included 'student lack of clear aims'. One teacher added 'student inability to learn English'. 'Poor adaptation to the campus' was also mentioned, along with a 'lack of activities on the campus to pursue.'

\subsection{Comments on Teacher Perceptions}

That transport to the campus appears in pole position by some distance is unsurprising. The university was fairly recently opened and bus and train journeys from the city to the suburb where the campus was located were 
overcrowded and infrequent. In the case of trains it also involved a long walk from the nearest station through bleak and often muddy backstreets. Disliking teachers and, to a much greater degree, disliking lessons were each highly placed, indicating that teachers had empirical evidence that students had issues with both. As with outcomes noted by Longhurst (1999), interviews with students failed to elicit much evidence of this.

\section{Student Perceptions}

Preparatory-level teachers were asked to distribute the same questionnaire to five classes of approximately twenty-five students. After collecting a hundred and twenty of them (and discarding eleven that were ruined), a representative sample of 109 completed questionnaires was analysed by SPSS, providing data shown in Table 4 .

Table 4. Student reasons for absence

\begin{tabular}{lcc}
\hline Reason & Number of times selected & Mean score \\
\hline Transport & 105 & 8.75 \\
Social activities & 94 & 6.81 \\
Weather & 87 & 6.64 \\
\hline
\end{tabular}

\subsection{Comparison of Teacher and Student Perceptions}

Although data in tables three and four reflect a strong correlation concerning nine of the thirteen items, it is firstly clear that teachers feel students are fairly unlikely to be absent due to inclement weather conditions, while students ranked this as the third most likely. Secondly, whereas teachers placed doing homework as the least likely item, students ranked this as the fourth most likely. More importantly, whereas students felt a dislike of language lessons and teachers would be the least likely reason to cause absence, teachers themselves had indicated that not liking language lessons and teachers would be high on the list of reasons for non-attendance. It is worth noting that dislike of lessons for both teachers and students were considered more likely reasons than dislike of teachers. Student interviews in the first semester elicited only brief references to such dislikes, although follow-up interviews revealed more.

\subsection{Comments}

As mentioned earlier in this study, not among the listed items but mentioned by three teachers and twenty out of 109 student responses was sleeping disorders. This was an issue that constantly appeared in student interviews later in the study and, as earlier noted, was also mentioned by Batı et al. (2012) as a key reason for non-attendance. Other reasons not listed included homesickness, the unfairness of the teaching time-table (separated into morning classes for A1 and afternoons for A2) and boredom on the campus.

\section{Analysis Part Two: Individual Interviews}

In order to gain an 'emic' (insider's perspective) on how reasons for absence related to the data gained from the questionnaire survey illustrated in Tables 3 and 4, I interviewed ten students who were well on the way to becoming an SFDA. In order to select them,I was provided with a list of names of those who by the middle of semester one had missed at least half of the amount of lessons allowed.Tenstudents agreed to be interviewed. With their permission all interviews were recorded in my office, either in English (where possible) or with the help of a teacher of English they knew, or a bilingual secretary who was available. As interviewees' responses in semester one were often interpreted by their own teacher, this may of course have inhibited matters. The cases were firstly a convenience sample, while at the same time, as they were all potential SFDAs, they were also a criterion sample.

In semi-structured individual interviews that were preceded by explanations in Turkish about promises of anonymity and how their help would assist the study, students were asked to explain as truthfully as possible why they were in such a potentially perilous position. Most of the reasons provided were logistical or personal, which is reflected in data revealed in the earlier questionnaire. Follow-up interviews were conducted by me in a combination of English and, where necessary, in Turkish.

\subsection{Individual Student Cases}

Each student was interviewed twice and informed they could read my accounts at any time but only via an appointment. The first figure records how many lessons each had missed prior to interview one. The second records how many they had missed prior to the second. 
Case One: 50 / 85

A male student, who was intending to study Tourism Guidance. He was currently living alone in a rented flat near to the campus. He complained firstly of infrequent morning bus services. The second reason was his friend, who tended to visit quite frequently. His main reason, however, was related to finance. As he did not at the start of the semester have the money to pay for course books, and as the teacher involved had indicated those without such material would be marked absent, he felt he might as well stay at home and avoid the humiliation. He admitted that these problems could be solved, but added that his personality tended towards idleness. This was exemplified by the fact that he was in a class at a level for which his English was far too good. He had, however, missed the start of term placement exam due to oversleeping.

The follow-up interview revealed that he followed carefully the amount of lessons he had missed. This currently stood at 85 , which meant if he missed four more for any reason he would be an SFDA. He said he had missed no lessons for two months, due mainly to the removal from his life of the distractions that had led to his 50 lessons missed. He admitted that boredom with lessons due to the difference in his own language-proficiency level and those of his peers was a contributing factor to his earlier absence, but added that had he known the exam he had missed due to over-sleeping would have such a consequence, he would have made a greater effort. He had recently been correctly informed that as he was planning to enter the Tourism department, he would pass even if he exceeded eighty-eight lessons. He completed the year with 86 lessons' absence and passed the Proficiency exam.

\section{Case Two: 44 / 69}

A female student intending to study Dentistry. She was currently living in a dormitory with several girls from various cities. She confided thatearly in the semester she had taken a one-week holiday on a boat with a friend. She explained how waking with feelings of melancholy often prevented her from attending morning classes, which were generally 'Main Course' lessons (as opposed to skills courses), and which she described as 'too serious lessons..which I can't stand'. She ended by saying “ the problem for me is my personality...and better transport to the campus would not make much difference..my problem is with me..I must make myself more content."

In the follow-up interview she explained how she had to force herself to attend lessons at times, and repeated how her emotional problems and having few close friends often caused her to be absent. She admitted she was more interested in Speaking and Writing courses, and more likely to miss classes from the main course. She ended by explaining her belief that her friends might admit to being satisfied with the English courses in general, but got the impression they were, on the whole, reluctant learners who were at university only because their family insisted on this. She ended the year with 78 lessons' absence and passed the Proficiency exam.

Case Three: 75 / 84

A male student from Istanbul, now living in a dormitory outside the city. Reasons for his absence, he explained were spending time with girlfriend and other class friends, plus spending time in parts of the city popular with young people. Along with transport to the campus, being unable to wake up in time was the reason that most of the lessons he missed were in the morning. He was intending to pursue a degree in Tourism Management.

In the follow-up interview, by which time he had only missed a further nine lessons, he explained how his level of attendance had improved after he asked the dormitory administrators for a daily wake-up call. Other reasons for this improvement were his discovering a better route to the campus, plus the fact that he had broken up with his girlfriend recently. Although he tended to miss Reading and Writing lessons, he was generally satisfied with the English course. He ended the year on 87 lessons' absence but failed the Proficiency exam.

\section{Case Four: 74 / 85}

A female student intending to study Tourism Management. She was an only child living with her parents a fairly long way outside the city. She had missed twenty-two lesson while on holiday in a central European country with her mother. The timing of the holiday early in the semester was due to receiving her passport late. Being unable to wake up meant starting late on what was at times a two hour journey to the campus. Soon after this interview, along with five others in her class, she was found to have altered the daily register in order to conceal her absence on several Fridays. More details about this appear in teacher interview two later in this study.

In the follow-up interview, although she had by this stage missed 85 lessons, being able to shorten the journey by travelling in a friend's car on two days a week had helped her. Like other interviewees in this study she was satisfied with the English courses, but rather bored at times since she was in a class much lower than her language level suggested. She explained how the importance of the placement exam at the beginning of the 
academic year had not been made clear to her, and had felt that just answering a few questions would enable her to attend the Prep' class in a mixed-ability class. Although untrue, she felt that as she was intending to pursuea degree in Tourism she did not need to pass the exam, and added, "I attend because my parents force me." She ended the year on 87 lessons' absence and passed the Proficiency exam.

\section{Case Five: $75 / 84$}

A male student from the north of Turkey who was living in a student dormitory only minutes away on foot from the campus. He was planning to pursue a degree in Tourism Management. Due to adaptation problems, however, he was unable to wake up in time for the first lesson, after which he had no desire to attend later lessons. He was confident that after overcoming this problem he would not become an SFDA. The follow-up interview revealed that he had adapted to university life to a degree and, although he still had sleeping problems, had missed very few lessons since the last time we spoke. He ended the year on 86 lessons' absence and failed the Proficiency exam.

\section{Case Six: 86 / SFDA}

A female student from south-east Turkey who was planning to study Tourism Management. She was at the start of the year living in a student dormitory a considerable distance from the campus. Realising the difficulty of using public transport, she had moved to a nearby private dormitory. Although missing only two more lessons would mean she had failed the year, she was confident she would still be on the class register at the end of it. She was not available for a follow-up interview, however, as by the middle of the second semester she had exceeded the limit of eighty-eight lessons absence and had become an SFDA statistic.

Case Seven: 58 / 83

A female student from northern Turkey who was planning to study Sociology. She lived in a student dormitory and was unable to get up in time to make the fairly long journey to the campus. In order to solve her problem she planned to move into the university dormitory on the campus which was due to open soon. I never discovered if she had solved her problem sinceearly in semester two she was the third interviewee in this study to become an SFDA statistic. However, since her department was not in English, she had, at least technically, passed the year.

Case Eight: 58 / 68

A female student living with her parents on the other side of the city. To reach the campus she had to take a train, a boat and then a bus. She was intending to study Tourism Management. She had missed most of her lessons in the first semester due to a two-week illness. Others were missed due to follow-up medical tests. She was aware of her situation as she regularly checked the website listing absence rates. From time to time her teacher discussed the issue of absenteeism with the class. She felt that apart from difficulties of travelling in poor weather conditions, some students would not come due to their poor ability in learning English. The follow-up interview revealed that she had missed only ten more lessons since the last time we spoke. She ended the year on 82 lessons' absence and failed the Proficiency exam.

\section{Case Nine: 75 / SFDA}

A male student from a city three hours away from the university who was living in a student dormitory on the outskirts of the city. He was planning to study Business Administration. Although a family illness had led to fifteen missing lessons, he admitted that he had not liked the university, his classmates and studying English. He was confident that he would not miss any of the eight remaining lessons before he failed the year. He was, however, not available for a follow-up interview as early in the second semester he had exceeded the limit of eighty-eight lessons absence and had become an SFDA statistic. As with case seven, since his department was not taught in English, he passed the year.

\section{Case Ten: $50 / 78$}

A male student from a city three hours away from the university who was living in a student dormitory next door to the university. He was planning to study Business Administration. Initially he had not liked the university, partly due to its location but mainly because it was not as he had imagined it would be. The reasons he provided for absence were visiting and being visited by friends, sleeping late and being unable to get up in time for the bus He had started a weekend course in an attempt to improve his English. In the follow-up interview he said that mixing up the classes had helped solve his problem as he was now in a more friendly and relaxed classroom atmosphere. As a result he was more willing to attend. He ended the year on 86 lessons' absence and failed the proficiency exam. 


\subsection{Teacher Interviews}

In order to carry out data triangulation, while continuing interviews with students, in order to gain further insights I interviewed teachers to get their perspective on the case of the SFDA. Five teachers were interviewed: two with little experience, two with considerable experience and one experienced teacher / senior administrator. All were teaching classes at A1 level. Questions asked in these interviews appear in Appendix 2 and were intended to probe the extent to which teachers' words and actions perhaps affected students' attendance.

Teacher One was in her second year of teaching and felt students were mostly, but not always truthful when answering interview questions, and added "They probably do not understand the importance of acquiring sufficient English for their future faculty studies." Concerning one student, whose responses she had interpreted for me, she commented that "X has a lazy attitude towards study but would not admit it." In class, on occasions she reminded her students about the possibility of failing due to absenteeism but provided no clear help. She felt sleep problems were probably caused by spending too much time on social networking and commented "Being away from family for the first time did not help." She rarely checked student absenteeism on the system. She confided that in fact two of her students had already become SFDAs but had been allowed to return to the university, but felt it would be a good idea not to ask the administration exactly why. When students had missed several lessons she provided help by telling them what they had missed and encouraged them to study more. She felt students with a poor grasp of English were those most likely to absent themselves in order to study for exams. She felt that more homogenous groups might assist in making teaching more appropriate, adding that weaker students would not feel humiliated in the presence of those with an excellent grasp of English.

Teacher Two was in his first year of teaching and felt many potential SFDAs had strong financial support from their family. He commented that "Students here say they have problems with transport but I think they are just irresponsible." He added how international students asked questions often, during lessons and in breaks, something which he found Turkish students rarely did. He told his classes how, if they failed to take advantage of the prep' year, they would pay much more for English courses later in life. Over a period of three weeks, six of his students had used correction fluid to enable them to sign the register for lessons they had earlier in the week missed; one of these was student Case Four. Numbers of lessons signed for illegally ranged from nine to twenty. This was discovered by administrators when hard copies of the register were handed in. In order to warn students, he occasionally took computer screen-shots that showed the list of absenteeism recorded. He felt that students should feel privileged to be at although their overall attitude failed to reflect this.

Teacher Three was in her tenth year of teaching and, based on her experience, felt success in English was related to attendance. "Students who don't attend regularly start to get lower marks in the exams and then fail."At the start of the year she told students about this and advised them to be absent only when most of their friends were too, thus avoiding having to teach very small groups. However, she noted that her comments were not very effective as "Students are away from home for the first time and probably enjoying the absence of parental pressure as well as feeling the relief of having overcome the stress of the Turkish university entrance exam system." She was unclear on how many lessons students could miss before they became an SFDA statistic, but felt that lowering the current limit of $15 \%$ might encourage attendance. She felt attendance was related to the relationship with the teacher, but admitted only a small number of students would study outside lessons. She commented that she would never give her phone number to students but when they returned from prolonged periods of absence she would ask what the problem was. She admitted that she did not have close relationships with students. She recalled that at her previous university there was psychological support for students on the campus. She felt that responsibility for talking to the class about attendance lay mainly in the hands of their main course teacher who saw them on a more regular basis. She ended by adding that some students were unhappy with the department in which they had been accepted and, while studying the prep' year, were also studying to re-take the university entrance exam.

Teacher Four was in her fourth year of teaching and commented how "If they like the teacher's style and if they like the atmosphere, students generally attend." She felt that constantly talking to students about absenteeism would have a negative effect and tended to focus instead on the positives of attending. She believed there was a strong relationship between attendance and success in language learning. She felt students stopped coming when they lost interest, and that they were not telling the truth when they said their reasons for being absent were not related to the classroom. "They don't want to talk about it, they fear that you or their friends might not like them anymore if they say 'teacher this is because of you'." When she asked students why they'd missed lessons they tended to say nothing. She added that in order to encourage attendance teachers should talk to students individually, even about seemingly minor matters such as their seating position in the classroom. 
Teacher Five was in her tenth year of teaching, and working at CK as a teacher and senior administrator. She had previously worked at two well-known Turkish universities. Her perception was that student absenteeism at CK was on the increase. She felt students expected something other than a university with such a drab campus in rather a bleak area, and felt transport to the campus, although much improved, was still an issue. A few students, she noted, were sometimes absent due to employment. Sometimes in English and at other times in Turkish she talked to the class about attendance, but felt constantly talking about the same issue would deter students from attending. In meetings with teachers she occasionally asked them to remind students about the benefits of attending.Instead of being proactive, she felt it was better to wait for students to initiate dialogue about why they absented themselves.

\subsection{Interview with Student Counsellor}

Following all student and teacher interviews I interviewed the university student counsellor, who is responsible for dealing with matters such as students' anxiety, depression, and among other things, emotional problems. She told me that students who arranged appointments with her never actually raised the topic of absenteeism, although clearly their problems might result in or from this. When she listed at my request the matters that students came to talk to her about, she was surprised when I informed her that, although it was not in her list, sleeping disorders was at or near the top of my own. Her description of the type of students who she frequently dealt with was close to those described as follows: students away from home for the first time, generally unable to look after themselves. Following this meeting I sent out a brief survey to all ten cases in this study to assess their awareness even of the existence of the student counselling service. None of them knew of this.

\section{Findings: Student Persepctives}

Interviews with students revealed how reasons for their absence bore partial relation to items on the initial survey (Appendix One). This study, while accepting there may be limitations concerning generalisability (Duff, 2008), revealed that characteristics of potential and actual SFDAs were as follows: they tended to be those from cities far away who lived in state run dormitories far away from the campus and who, as a result of logistical reasons and personal adaptation problems, principally sleeping disorders, found it difficult to attend language lessons on a regular basis. In some cases, clearly too late for three of the ten in this study, they took steps to avoid becoming an SFDA statistic. Although clearly a contributary factor, yet scarcely alluded to in interviews, absenteeism due to language learning or teaching related matters appears relatively marginal. It would appear that students from the Tourism faculty in particular - six of the ten cases here - are prevalent among the SFDA statistics.

The overall reality is stark. Seven out of the ten cases in this study failed the year, contributing to the fact that each academic year SFDAs at CK amount to approximately $20 \%$ of the original preparatory year intake and are largely from classes at A1 (beginner) level. Too often such students realise late that records of their absence are taken seriously by the university and are recorded in a regularly updated database. Adopting a 'jam today' approach to life, which one might reasonably expect among late-teenagers, students appear to use up the overwhelming majority of their allowed absence in the first semester. When they begin to comprehend their perilous situation some take a proactive stance by, for example, relocating to nearer the campus or developing a greater degree of self-discipline. Others, though, are not beyond resorting to manipulating attendance records in the hope that they will not be found out. Teacher interviews revealed how students are often made aware of the perils that absenteeism may cause, although this is largely ineffective and more might be done on this matter. The fight against absenteeism is not helped by the fact that SFDAs (cases six, seven and nine in this study) are now able to enter the summer school in order to take the language proficiency exam, nor by the fact that those planning to enter departments which teach only in Turkish (cases one, seven, and nine in this study) may do so even after becoming an SFDA and without taking the summer school.

\section{Implications}

Ensuring all students are fully aware of the availability of help from the student counselling service would be beneficial in the struggle to decrease absenteeism. Such a person might invite attendance at presentations which deal with matters causing absenteeism, such as sleeping disorders. Implementing a mentoring system, whereby teachers could be more responsible for discussing a student's continued absence, may be one possible action point. As an alternative, a student 'buddy' system might be implemented, one within which each student was responsible for the overall well-being of another. One means of motivating students with a poor record of attendance might be to provide course work online. However fanciful it may sound, if students could demonstrate that they had 'worked from home' then they might be considered as being 'present' on the register for even a few lessons per week. Furthermore, clear explanations of the role and importance of the English Language Placement Exam at the start of the academic year would help avoid unnecessary boredom, a feature 
this study highlighted as resulting in absence due to students being placed in the wrong level. Perhaps more draconian, enforcing a financial penalty on SFDAs might help focus minds a little more.

\section{References}

Bat, A. H., Mandiricioğlu, A., Orgun, F., \& Govsa, F. (2012). Why do students miss lectures? A study of lecture attendance amongst students of health science. Nurse Education Today, 33(6).

Burd, L., \& Hodgson, B. (2006). Attendance and attainment: A five year study. ITALICS, 5. http://dx.doi.org/10.11120/ital.2006.05020004

Cleary-Holdforth, J. (2007). Student non-attendance in higher education. A phenomenon of student apathy or poor pedagogy? Dublin Institute of Technology Publication.

Duff, P. A. (2008). Case Study Research in Applied Linguistics. Lawrence Eralbaum Associates.

Ervin, A. M. (2000). Applied anthropology: Tools and Perspectives for Contemporary Practice. Boston: Allyn and Bacon.

Gall, J. P., Gall, M. D., \& Borg, S. (2005). Applying Educational Research: A Practical Guide. Boston: Allyn and Bacon.

Gerring, J. (2007). Case Study Research: Principles and Practices. Cambridge: Cambridge University Press.

Longhurst, R. J., (1999).Why Aren't They Here? Student absenteeism in a further education college. Journal of Further and Higher Education, 23(1), 61-80. http://dx.doi.org/10.1080/0309877990230106

Richards, K. (2011).Case Study. In Handbook of Research in Second Language Teaching and Learning (Volume II), 207- 221. New York: Routledge.

Romer. D. (1993). Do students go to class? Should they? Journal of Economic Perspectives, 7, 167-174. http://dx.doi.org/10.1257/jep.7.3.167

Schalge, L. S., \& Soga, K. (2008). "Then I stop coming to school”: Understanding Absenteeism in an Adult English as a Second Language Program. Adult Basic Education and Literacy Journal, 2(3). 151-161.

Schutt, R. K. (2006). Investigating the social world: The Process and Practice of Research. SAGE.

Stake, R. E. (1995). The Art of Case Study Research. Thousand Oaks, CA. SAGE.

\section{Appendix 1: Research Survey}

Dear Student, I am carrying out a research project which concerns investigating reasons for prep' student absenteeism. Could you please think about your answers carefully and then list the correct order of reasons for your absence thus far this semester. CHOOSE YOUR TOP TEN ONLY. This is not a test, so please be as truthful as you can. I promise to share the results with you in 2015. When you have finished, please place it in an envelope and seal it then give it either to your Main Course teacher or to me. Thank you for your cooperation.

\section{Part A:}

Name (optional):

I am: Male / Female Faculty / Department:

\begin{tabular}{|c|c|}
\hline Family obligations & ( \\
\hline Weather condition & ( \\
\hline Social activities & ( \\
\hline Doing course / homework & ( \\
\hline Studying for exams & ( \\
\hline Transport problem & ( \\
\hline With friends from & ( \\
\hline With friends not from & ( \\
\hline Unofficial Holidays & ( \\
\hline Seeing boy/girlfriend & ( \\
\hline
\end{tabular}




\begin{tabular}{lll}
\hline Work commitments & ( & ) \\
Dislike studying English & ( & ) \\
Dislike Teacher(s) & ( & ) \\
Other reason(s) (please explain) & ( & ) \\
\hline
\end{tabular}

\section{Part B:}

Optıonal: I am available later this week to be interviewed for 5- 10 minutes (in Turkish) and understand that although parts of the interview may be used in the research article, my identity will not be disclosed to anyone apart from the interviewer.

My name is:

Class Number:

\section{Appendix 2: Teacher Interview Questions}

What are your thoughts in general about student absenteeism at prep' level?

What are your thoughts about students being absent from your lessons?

How often do you talk to them as a class or individually about absence?

What do you say? What do they say? How effective is it? Any evidence?

Do you know where to go to find out how many lessons students have missed? Where?

Do you know how many lessons they can miss before they fail? What do you think about this number?

How many of your students have failed this year due to absenteeism? Who are they?

How many of your students are close to failing at the moment? Who are they?

When you notice students are or have been absent, what do you do?

When they return, what do you do?

What do you think you or others could or should do to encourage absent students to attend more often?

\section{Copyrights}

Copyright for this article is retained by the author(s), with first publication rights granted to the journal.

This is an open-access article distributed under the terms and conditions of the Creative Commons Attribution license (http://creativecommons.org/licenses/by/3.0/). 